\title{
NARRATIVAS DE ESTUDANTES, FILHOS DE CATADORES DE MATERIAIS RECICLÁVEIS, SUAS FAMÍLIAS E AS RELAÇÕES ESTABELECIDAS
}

\section{CLÁUDIA MORAES DA COSTA VIEIRA}

https://orcid.org/0000-0001-5635-1449

Secretaria de Educação do Distrito Federal Universidade de Brasília

RESUMO Uma questão recorrente no contexto escolar é a indagação de como a escola lida com os estudantes advindos da classe popular, em especial os pertencentes ao grupo de catadores de material reciclável, já que a própria estrutura histórica, social e cultural dessa instituição apresenta-se como exclusão para o grupo. O presente artigo tem como objetivo geral compreender a partir do olhar dos estudantes, filhos de catadores de material reciclável, o grupo familiar e as relações estabelecidas nesse núcleo. Participaram deste trabalho 65 estudantes do 40 ano do ensino fundamental, com média de idade de 10 e 13 anos (35 meninas; 30 meninos), sendo 36 residentes na ocupação Santa Luzia, e 29 na Região Administrativa Estrutural, do Distrito Federal. A pesquisa foi constituída a partir da adoção do método autoecobiográfico que envolveu a participação nas oficinas autoecobiográficas, a observação participante e as entrevistas. Ao articular os dispositivos para a constituição das narrativas, chegouse ao encontro da análise interpretativa das fontes biográficas. Pode-se inferir que a família para esses estudantes é um território das relações afetivas, no qual o trabalho e a vida se entrelaçam e definem papéis e estratégias de sobrevivência.

Palavras-chaves: Estudantes. Catadores. Material reciclável. Família.

\section{ABSTRACT NARRATIVES OF STUDENTS CHILDREN OF RECYCLABLE MATERIAL COLLECTORS, THEIR FAMILIES AND THE ESTABLISHED RELATIONSHIPS}

A recurring matter in the academic context is the question of how the school deals with students who come from the working class, in particular those belonging to the group of recyclable material collectors, since the historical, social and cultural structure of this institution presents itself as exclusion for this group. The present 
article aims to understand, from the perspective of students children of recyclable material collectors, the familial group and the relationships established in this nucleus. 65 students of the 4th year of elementary school participated in this study, with an average age of 10.75 years ( 35 girls; 30 boys), of whom 36 were residents of the Santa Luzia settlement, and 29 of the Structural Administrative Region, in the Federal District. The research pathway was hinged on the autoecobiographic method, which involved the participation in the autoecobiographic workshops, participant observation and semi-structured interviews. The articulation of the strategies for the constitution of the narratives was consistent with the interpretative analysis of the biographical sources. It can be concluded that to those students, family is a territory of affective relationships, wherein work and life intertwine and define roles and strategies of survival.

Keywords: Students. Collectors. Recyclable material. Family.

RESUMEN NARRATIVAS DE ESTUDIANTES, HIJOS DE

\section{RECOLECTORES DE MATERIALES RECICLABLES, SUS FAMILIAS Y LAS RELACIONES ESTABELECIDAS}

Una pregunta recurrente en el contexto escolar es la cuestión de cómo la escuela trata con los estudiantes de la clase popular, especialmente aquellos que pertenecen al grupo de recolectores de materiales reciclables, ya que la estructura histórica, social y cultural de esta institución se presenta como exclusión para el grupo. Este artículo tiene el objetivo general de comprender desde la perspectiva de los estudiantes, hijos de recolectores de materiales reciclables, el grupo familiar y las relaciones establecidas en este núcleo. Participaron en este estudio 65 estudiantes del cuarto año de la escuela primaria, con una edad promedio de 10.75 años (35 niñas; 30 niños), 36 de los cuales residían en la localidad de Santa Luzia y 29 en la Región Administrativa llamada Estrutural, del Distrito Federal. La trayectoria de la investigación se formó con base en el método autoecobiográfico, que involucró la participación en talleres autoecobiográficos, observación participante y entrevistas semiestructuradas. Al articular las estrategias para la constitución de las narrativas, encontró un análisis interpretativo de las fuentes biográficas. Se puede inferir que la familia para estos estudiantes es un territorio de relaciones afectivas, donde el trabajo y la vida están entrelazados y definen roles y estrategias para la supervivencia.

Palabras clave: Estudiantes. Recolectores. Materiales reciclables. Familia. 


\section{Introdução}

A catação de material reciclável é um processo antigo que veio a ser valorizado a partir dos movimentos ambientalistas em prol de uma possivel sustentabilidade, mas que ainda carrega o estigma, que vem desde a Idade Média, quando somente algumas pessoas eram destinadas a trabalhar no destino final do lixo, de acordo com a sua condição marginal, de prisioneiros, prostitutas, escravos, mendigos etc. Esses eram os sujeitos responsáveis por resolver o problema do que era considerado como resto (BARBOZA, 2012; VELLOSO, 2008).

Alguns autores, como Dias (2009), apresentam a dificuldade de se constituir o fenômeno dos catadores e da catação enquanto campo de estudo científico. Essa questão é apontada no Brasil e no mundo. Isso passa a ser considerado a partir de alguns aspectos, como: (a) o fluxo dos que entram e saem dessa ocupação; (b) o medo que alguns catadores têm de dar informações sobre a sua ocupação, pelo fato de correrem riscos por não poderem atuar em determinados locais; e (c) a invisibilidade desses indivíduos nas estatísticas oficiais. Esses são aspectos que, de certa forma, dificultam a literatura que aborda o tema.

Birkbeck (1978) foi um dos primeiros a reconhecer o fenômeno dos catadores, denominando-os de "self-employed prolelarians", proletários independentes.' O autor considera que esse grupo se autoemprega. Contudo, esse fato constitui uma ilusão. Esses trabalhadores têm o sentimento de controle sobre o próprio trabalho, mas, na realidade, trabalham de forma indireta para as empresas e as indústrias de reciclagem. São elas que fazem o controle do preço e da venda, enquanto os catadores não têm vínculo empregatício com estes grupos empresariais. Outro fator reconhecido foi a relação entre os catadores e o setor formal

1 Tradução livre. de reciclagem, no Lixão de Cali (Colômbia). Situação também encontrada nas pesquisas realizadas no Brasil, com os trabalhos de Feitosa (2011), o qual mostra que os catadores passaram a ser reconhecidos como subalternos à cadeia de reciclagem. Nas pesquisas de Teixeira (2010), Costa e Pato (2016), Costa (2016), Magera (2012), há um reconhecimento das relações que esses trabalhadores têm com os conhecidos "atravessadores" e com as empresas de reciclagem que se encaminham aos locais para comprar o material coletado.

No Brasil, de acordo com o levantamento do Instituto Brasileiro de Geografia Estatística (IBGE) de 2011, em uma pesquisa realizada no ano de 2008, havia 70 mil catadores nas áreas urbanas, sendo que $8 \%$ tinham até 14 anos (5.636), e 92\% estavam acima de 14 anos (64.813). No mesmo documento, verifica-se que há dados diferentes, e mesmo contraditórios, no que se refere ao índice quantitativo dos catadores apresentado pelos movimentos sociais, instituições do terceiro setor e órgãos governamentais. O Movimento dos Catadores de Material Reciclável (MNCMR) afirma que há mais de 800 mil catadores, enquanto outras fontes apontam 500 mil (PóLIS, 2006). 0 documento indica que com essa diferença numérica de estatística há um "[...] intervalo razoavelmente seguro, no entanto bastante amplo. Vai de 400 mil a 600 mil indivíduos, estimado com base apenas na dispersão dos números citados nas diversas fontes" (BENSEN, 2008, p. 13). Para Bensen (2011), esse número era de aproximadamente 230 mil catadores, tendo como base os dados da Pesquisa Nacional por Amostra de Domicílio (Pnad) de 2006. 0 relatório de 2012 do Instituto de Pesquisa Aplicada (Ipea), referente às regiões, confirma a referência apresentada por Bensen (2011) que atualmente, no território brasileiro, o número de catadores chega a aproximadamente entre o intervalo de 400 a 600 mil. 
Januzzi (2001) caracteriza esse grupo como de "os indigentes" e Melo Filho (2005) os aponta como um resultado da concretização do Estado mínimo. 0 ator social subproletário marginal urbano seria o "elemento de transição para os futuros grupos de excluídos" (OLIVEIRA; FERNANDES; ALMEIDA, 2012, p. 56). Esse processo de transição se agravou no Brasil com a ditadura militar, de acordo com os autores citados, nos anos de 1964 a 1984. As desigualdades se agravaram, pois o capital vindo do exterior sustentava a mola propulsora das indústrias, o que aumentava o confronto no sentido de desmantelar as organizações que lutavam por melhorias salariais para os trabalhadores. Mesmo depois da retirada das forças armadas, as desigualdades continuaram crescendo, em especial no período de 1980 a 1988, havendo uma diminuição no emprego formal e uma ampliação do desemprego estrutural e também da precarização dos postos de trabalho.

Ao pesquisar a história de vida de um grupo de 20 catadores (COSTA, 2008), observouse uma identidade pautada pela exclusão, no sentido da segregação do direito à cidadania e da negação da dimensão humana. Três pontos encontrados nas narrativas de suas trajetórias de vida foram relevantes e direcionaram para uma identidade excludente: a) o trabalho infantil e suas consequências e marcas; b) as condições de extrema miséria vivenciadas no interior dos núcleos familiares; e c) o abandono da escola e a dificuldade de adaptação às estruturas dessa instituição.

No grupo de catadores, o trabalho infantil era caracterizado pelas vendas de produtos nos semáforos e em locais de movimento intenso, próximos à área comercial. As crianças iam se constituindo como pequenos trabalhadores que exercitavam diariamente lutas individuais intensas, para fugir das situações que os levavam à degradação humana: a prostitui- ção infantil, o consumo de drogas e os pequenos furtos.

A ação do trabalho dava-se no interior dos seus núcleos familiares, quando o trabatho dos pais acontecia fora da área geográfica da moradia; e as crianças mais velhas, alguns adolescentes ou mesmo crianças, ocupavam o lugar do responsável pelo núcleo familiar, incluindo a manutenção financeira. A pesquisa adotou como perspectiva metodológica princípios das histórias de vida, conforme sistematizados por Souza (2006) e Nóvoa (2010), dimensões da pesquisa (auto) biográfica com crianças (PASSEGGI, 2014) e as oficinas autoecobiograficas (COSTA; PATO, 2018) para a constituição e a análise pessoal e coletiva das histórias de vida dos estudantes filhos de catadores de material reciclável, pois considerou o território das histórias de vida como: (auto)biográfico, dialógico, amoroso e complexo, e, concomitantemente, reflexivo e interventivo.

As histórias de vidas são consideradas como o território de constituição de saberes, fazeres, sentidos e valores, que vão revelando elementos constituídos no ambiente local, individual, coletivo, e aproximando as pessoas da sua realidade. 0 cotidiano passa a ser refletido, lembrado e articulado ao processo de existência, em um sentido de totalidade.

Adotou-se o método autoecobiográfico (COSTA, 2016) como espaço vivo, lúdico e de intervenção, que oportunizasse ao conhecimento, à compreensão e à sensibilidade e, concomitantemente, se constituísse em um espaço/ tempo de escuta e de compromisso com a relação dialógica, centrado em oficinas autoecobiográficas, observação participante e diário de campo.

As oficinas autoecobiograficas se constituíram a partir dos conceitos de auto (MORIN, 2005), eco (MOURÃO, 2012) e da perspectiva do 
conceito de sensivel (BOIS; AUSTRY). Os estudos e procedimentos de sistematizados por Josso (2008-2010), Lechner (2012) e os trabalhos de Delory-Momberger $(2006,2008)$, subsidiaram a produção da metodologia.

A análise baseou-se no método de análise interpretativa das fontes biográficas (SOUZA, 2004) em que a interpretação fenomenológica e a hermenêutica se constituem como processo contínuo em que se interligam todos os elementos do trabalho em uma perspectiva de aproximação do viver sentido e refletido.

O estudo foi realizado em uma escola pública pertencente à Secretaria de Estado de Educação do Distrito Federal (SEEDF), localizada na Cidade Estrutural, próxima ao local onde se encontra o aterro sanitário. Participaram deste estudo 65 estudantes do 4음 ano do ensino fundamental, sendo 35 meninas e 30 meninos. Foram estabelecidos os seguintes critérios para a participação: ser filho de pessoas que exerciam a ocupação de catadores de material reciclável; cursar o 4으 ano; aceitar ser voluntário da pesquisa; ter autorização de pais e professores.

Ao narrarem suas trajetórias de vida, a partir das oficinas autoecobiográficas (COSTA, 2016) o núcleo familiar foi se constituindo como um território pleno de afetos em que e em suas falas, gestos, registros, os participantes transmitiam sentimentos de proteção, amorosidade, aceitação e rejeição. De um ir e vir em direção de pais para filhos e filhos para pais.

São núcleos familiares que se constituem a partir da sobrevivência, da proteção e da segurança. 0 trabalho se constitui como base para essas famílias. Ele se mistura ao viver familiar, trazendo hábitos e costumes próprios.

Alguns desses estudantes participam do trabalho dos pais; outros vão ao aterro sanitário para recolher brinquedos; já outros conhecem a realidade do trabalho somente a partir de histórias contadas pelos pais ou irmãos mais velhos, já que seus pais não permitem sua presença naquele local.

Apesar de todos esses elementos dificultadores, os catadores são seres que não desistem "da vida, nem da catação e nem da cidade" (BARBOZA, 2012, p. 199). Vão ressignificando o sofrimento por meio das lutas permanentes, ao passo que reutilizam os materiais encontrados no processo da catação. Desse modo, vão transformando vida e trabalho em resistência e esperança.

\section{A família: os laços e os apertados nós}

A família vai se apresentando aos poucos, a partir da confirmação de serem filhos de catadores de material reciclável. Os estudantes revelam que pertencem a um grupo em que trabalho e vida se entrelaçam. Identifica-se ali a base de apoio e segurança para a grande maioria. Em outros casos, a ausência do apoio é revelada por pais e mães, pela circunstância da pouca idade e dos processos de exclusão que ainda vivenciam.

A família vai se constituindo nesse território em que se aprende desde cedo o valor de contribuírem uns com os outros e de participar da luta coletiva pela sobrevivência. Diante de diversas ausências que se estendem à falta de alguns membros da família, como os pais e irmãos mais velhos, esses estudantes precisam se mobilizar para aprender a suprir ou criar formas de preencher esse vazio.

O trabalho é um dos elementos que constitui a base de relação desses grupos familiares nos quais filhos e pais vivenciam diariamente o contexto dos que sobrevivem da catação. 0 cuidado que demonstraram nos relatos, evidenciando o trabalho dos pais, demonstra a relação entre o trabalho e o viver desses estudantes. A narrativa constitui-se, assim, como um exercício árduo, em especial, nos primeiros 
momentos, quando não havia se estabelecido ainda um clima de confiança entre os participantes e a pesquisadora.

Surgiram narrativas ainda cuidadosas, e, no seu interior, enumeravam-se os trechos de silêncio, mas misturados a algumas brincadeiras para se desviarem da discussão sobre a própria realidade. Como eventualmente alguns de seus colegas se referiam à atividade de catação com expressões pejorativas e depreciativas, muitos desses estudantes colaboradores, em seus relatos, procuravam apontar um outro familiar, como avó, tio, padrinho, irmão ou alguém próximo da família, como a pessoa responsável pelo trabalho no aterro sanitário. Essa forma de se protegerem dos preconceitos, acabava revelando também a vergonha que muitos sentem pela atividade exercida. Havia um cuidado meticuloso ao falar; alguns não se conheciam ou não sabiam da vida dos outros fora do ambiente escolar. Ou seja, embora estudassem na mesma sala de aula, não falavam muito de si uns com os outros.

Alguns deles encontravam-se fora da escola, no aterro sanitário, local onde seus pais trabalhavam. E demonstravam certa cumplicidade e até intimidade nesses momentos, o que os levava a manter certa proximidade, na sala de aula, e a constituírem pequenos grupos ou duplas.

Antônio (11 anos): Tia, eu e o Tadeu sai daqui e vai catar latinha, né? A gente entra lá pelo campo. Né? (Sorri muito).

Esses grupos ou duplas estavam sempre juntos. Alguns não ficavam tão próximos na sala de aula devido a determinações da organização do espaço da sala, mas, no decorrer dos recreios, era possivel observar que se encontravam e mantinham conversas, em um contexto de intimidade e proximidade que não poderia ser compartilhado com os demais colegas. Desse modo, eles iam se agrupando e construindo laços de amizade como forma de fortalecimento. Naqueles momentos de conversa, combinavam as idas ao aterro sanitário e desenvolviam parcerias, na procura do material reciclável.

Alguns relatos parecem desvelar os conflitos e contradições vividos por muitos desses estudantes desde cedo, com a mistura de sentimentos de orgulho e vergonha pelo trabalho exercido por seus pais de catar resíduos sólidos no aterro sanitário, conforme ilustrado no trecho a seguir:

Kédma (10 anos): Tem muita gente assim que trabalha de catadora e tem muito filho, assim, que tem vergonha de ter uma mãe catadora, mas eu não tenho, tenho muito orgulho de ter a minha catadora, ela me dá tudo, me dá boneca, me dá as coisas, assim, se não fosse por ela, eu não estaria na escola.

Nesse trecho, a estudante evidencia seu orgulho pelo trabalho exercido pela mãe por reconhecer que é a partir desse trabalho que sua mãe garante o sustento da família, sua manutenção material e o suporte para a educação formal que a menina recebe e à qual ela atribui um valor e uma importância. 0 trecho revela ainda o cuidado da mãe com a infância de seus filhos, ao se preocupar em levar brinquedos para eles, mesmo exercendo uma atividade que exige atenção e cautela para evitar acidentes. A admiração pela figura materna, entretanto, não a exime de refletir sobre a realidade e a vergonha que esse trabalho acarreta para alguns.

Joana lembrou que há um valor ambiental no trabalho de sua mãe:

Joana (10 anos): Eu acho esse negócio de reciclagem são muito bom pro meio ambiente, mas a pessoa não cuidam do meio ambiente, joga lixo na rua. Eu também achei bom minha mãe fazer esse trabalho, porque ela vai me ensinando como recicla as coisas [...].

Mais uma vez, a figura materna é citada. 0 trecho ilustra a aprendizagem que eles cons- 
troem com os pais, e as contribuições de seus trabalhos para a vida individual e das cidades. A reciclagem vai sendo apropriada por todo o núcleo familiar e constituindo saberes e fazeres próprios da especificidade da catação.

Esses aspectos também são identificados nos trabalhos de Barbosa (2012), Teixeira (2010) e Alterthum (2005). Trata-se de um saber advindo do viver e sobreviver da reciclagem. Percebe-se um vínculo entre o trabalho da reciclagem e o cuidado com o meio ambiente como forma de amenizar o dano causado pelo acúmulo e a produção de resíduos nas cidades, mas simultaneamente, sugere-se um olhar de desaprovação das pessoas e da sociedade, ao demonstrar o descuido que vem da ação de se jogar lixo em qualquer lugar. Com isso, considera-se a falta de consciência sobre a importância do meio ambiente e a própria desvalorização das questões ambientais e da figura do catador de material reciclável.

A desvalorização é refletida pelos participantes e ampliada a partir da descrição do ambiente de trabalho - o aterro sanitário -, como um local degradado e insalubre que pode oferecer riscos à saúde de quem lá trabaIha, conforme evidencia o trecho a seguir:

Laura (11 anos): Assim, como meu primo, ele trabalhava dentro do lixão, assim, às vezes, ele catava assim, ai ele pegou bicho no joelho e nos pés, assim, aí ele teve que ir no hospital pra cortar a perna. Ele pegou muita bactéria, assim, no lixão.

A degradação é expressa pelo mau odor dos resíduos em decomposição, pelo excesso de insetos e microrganismos nocivos provenientes do próprio lixo, e pelo contato direto do chorume com o solo e com as pessoas que trabalham no local. 0 aterro sanitário é considerado um ambiente que causa vários problemas de saúde. Com isso, geram-se problemas socioambientais; e, entre os diversos apontados, os mais visiveis são os danos físicos. Uma questão apontada pelos estudantes desse grupo foram as feridas no corpo, que ocasionavam irritação na pele e coceira. Segundo os relatos, mesmo indo ao posto de saúde e fazendo uso das medicações prescritas, com o decorrer do tempo, o problema voltava a ocorrer. A lagoa de chorume aparece nos relatos, com destaque para o odor que ela apresenta e que é sentido em quase toda a Cidade Estrutural, local onde vivem os participantes. Eles compreendem que ao tocar o solo, o chorume traz a contaminação.

Outro item considerado no aspecto do trabalho é a preocupação com a quantidade de acidentes que ocorrem diariamente no aterro sanitário, e o receio constante de perderem pessoas queridas, por presenciarem essas situações com pessoas próximas, muitas vezes do núcleo familiar. É uma circunstância rotineira na vida desses estudantes:

Gilberto (11 anos): Meu avó morreu ontem. A carreta passou por cima dele, lá no lixão.

Paulo (11 anos): Tia, lá tem um monte de acidente, já tocaro fogo no menino [...]

O trabalho dos pais estende-se a eles. Isso faz com que esses estudantes estejam vulneráveis a situações de violência e dor, sendo diariamente expostos a tais situações, como no caso do Paulo. Eles estão na escola por um pequeno tempo e, logo após, vivenciam acontecimentos dessa natureza, silenciam ou demonstram inquietação e diversas vezes traduzem a dor em violência. Percebe-se que, no ambiente escolar, não há um espaço de acolhimento para situações como essas.

Pedro mostrava-se silencioso e cabisbaixo, no início da oficina. No decorrer dos trabalhos, ao ouvir as histórias dos outros colegas, que expressavam angústias e dor, e/ou relatos dos acidentes ocorridos no lixão, expressou sua própria dor e angústia, compartilhando o que havia ocorrido com seu avô no dia anterior. 0 
espaço de escuta permitiu a expressão dos sentimentos e, simultaneamente, a identificação com o que estava sendo exposto.

São estudantes que vivenciam as consequências de um trabalho precário, em uma perspectiva de degradação humana e ambiental, de dor e desvalorização do trabalho e do próprio ser. Ação sentida e refletida, de um sofrimento profundo, sem qualquer olhar que contribua para a superação desse problema. Apesar dos avanços e discussões sobre a Política Pública de Resíduos Sólidos, diariamente, muitos catadores ainda morrem nos lixões e aterros sanitários dos grandes centros urbanos.

Outro aspecto percebido foi a concepção do trabalho como duro, pesado. Situação que também foi constatada quando da análise das trajetórias de vida dos catadores da Comunidade e Cooperativa Reciclo, no ano de 2008. Nas narrativas dos estudantes colaboradores, esse fato é considerado como o que os impulsiona a contribuir com o oficio de seus pais, assumindo um trabalho em família, feito por pais e filhos e, às vezes, com a participação de outros núcleos familiares.

Alguns familiares, em especial das regiões do entorno do Distrito Federal, como Águas Lindas de Goiás, vêm no final de semana para trabalhar no aterro sanitário, juntando-se aos que já estão ali. Os estudantes afirmavam que só colaboravam com os pais aos domingos, e viam essa atividade como uma oportunidade para brincar com outros colegas, ou parentes, como os próprios primos, que também iam ajudar os pais. Todos sabiam que não era permitida a presença de crianças no aterro sanitário, mas isso era resolvido com algumas estratégias, conforme expresso a seguir.

Clarice (10 anos): [...] eu vou ajudar meu pai, só de manhã, porque meu pai tem um saco assim (mostra com as mãos os gestos). Ele finge que é latinha, ai entra lá por trás e eles vai lá e deixa. Eu ajudo, depois procuro Barbie.
Os núcleos familiares vão trazendo diferenciações. Há um grupo em que os estudantes participam da coleta quase que diariamente. Os meninos, na condição de filhos mais velhos, têm a responsabilidade de contribuir com suas mães para carregarem os "bagues". Tomás vivenciava essa situação, mostrando-se sonolento, logo pela manhã, quando vinha de uma noite extensa de trabalho no aterro. Ele justificava que só colaborava quando a situação financeira da família estava dificil. Esse trabalho só é reservado para as meninas quando estão mais velhas. Em sua maioria, as meninas cuidam dos irmãos e da casa, enquanto os pais trabalham no aterro.

O cuidado que os participantes tinham ao falar das estratégias que utilizavam para colaborar com os pais era evidenciado sempre que se iniciava a conversa. Inicialmente, eles reafirmavam o discurso legal e institucional aprendido nos projetos que frequentavam no contraturno, e em algumas cooperativas em que os pais trabalhavam. A frase era uma só, de que crianças não deveriam frequentar o aterro, mas, sim, a escola. Alguns estendiam essa referência também aos adolescentes e definiam que a idade para se iniciar o trabalho era a de 14 anos. Revelavam a preocupação de seus pais perderem a guarda familiar, pois, alguns deles já haviam passado por essa situação e não queriam vivenciar novamente a experiência.

Paulo (11 anos): Tia, eu mermo já morei debaixo da ponte. Mas o Conselho tutelar me pegou. Aí, minha mãe conseguiu uma casa na Estrutural, nas casinhas, ai eu saí do abrigo.

Paulo relata uma realidade conhecida por ele desde muito pequeno. Ele havia passado por diversos abrigos até chegar a morar com sua família. 0 desejo de permanecer próximo

2 Bagues: a maneira que os catadores denominavam as sacolas grandes, confeccionadas de lona, para armazenarem o material recolhido no trabalho da catação. 
do núcleo familiar o deixava receoso de revelar que durante alguns dias da semana contribuía com o trabalho de sua mãe no Aterro, isso porque o fato de conviver atualmente com a sua genitora era uma conquista resultante de uma intensa luta travada por ela.

Foram várias idas e vindas. Contudo, com o trabalho, sua mãe pôde voltar a ter um espaço coletivo de convívio com a família. A mãe é considerada, por ele, como uma heroína, pois, em nenhum momento, ele percebeu nela sinais de desistência. 0 valor que ele atribui à mãe se fortalece ainda mais quando passa a conviver exclusivamente com ela em uma casa na Cidade Estrutural, já que seu pai se encontrava recluso no sistema prisional.

Por outro lado, alguns desses meninos e meninas, mesmo convivendo nesse contexto de trabalho precoce, eram oriundos de uma outra realidade, e moravam em locais considerados seguros - ainda que na Ocupação Santa Luzia -, com seus familiares, o que significava segurança, proteção e cuidado, mesmo na convivência com a precariedade.

As diferenças entre esses núcleos foram se confirmando ao longo do trabalho. Alguns pais trabalhavam no aterro, mas não permitiam que as crianças estivessem naquele local. Algumas vezes, eles levavam os filhos para "procurarem brinquedos", mas só permitiam que "trabalhassem" em locais que consideravam seguros. Outros precisavam da contribuição dos filhos, em especial, o mais velho do núcleo. Muitas vezes, também os meninos mais novos contribuíam com o trabalho, em especial, nos grupos que tinham a figura materna como núcleo central. Outros, ainda, em um número menor, conheciam apenas a entrada do lixão por ela ficar próxima de uma associação em que eles participam de atividades esportivas no contraturno das aulas. Seu contato com essa realidade se dava por meio dos brinquedos e objetos trazidos por seus pais e irmãos mais velhos, ou pelos relatos que estes faziam a respeito de suas experiências lá. Esse panorama tão diverso evidencia o fato de que mesmo em grupos com realidades próximas, no aspecto do trabaIho e da própria condição social, há compreensões diferentes da infância e da criança que são provenientes das diferentes configurações que constituem os diversos núcleos familiares.

Há grupos que constituem uma relação de afeto, conforme os estudos de Barboza (2012). A afetividade aqui é tomada a partir de Freire (1997), no sentido da amorosidade, na perspectiva de considerar que todo ser humano tem a capacidade de amar e de buscar uma dignidade individual e coletiva; um comprometer-se consigo, com o outro e com as diferenças, na perspectiva de um processo de solidariedade com a humanidade. Nesse sentido, Ferreira (2011) compreende que a afetividade perpassa toda a ação humana no processo de sua existência, pois o pensar e o sentir estão associados, e os afetos são considerados como as emoções e os sentimentos. Para Sawaia, a afetividade se apresenta como:

[...] tonalidade, cor emocional que impregna a existência do ser humano e é vivida como: 1) sentimento: reações moderadas de prazer e desprazer que não se referem a objetivos específicos; 2) emoção: fenômeno intenso, breve e centrado em objeto que interrompe o fluxo normal da conduta. (SAWAIA, 1999, p. 2)

Assim, o processo de afetividade pode se constituir como uma mola propulsora de libertação e/ou escravização da sociedade. Nesse sentido, a afetividade é vista como uma atribuição de significado à vivência do indivíduo na sociedade, em sua forma de atuar no mundo, seu modo de afetar e ser afetado, que pode originar o que a autora denomina de "sofrimento ético político". Essa situação ocorre quando o ser, pela forma de exclusão social que sofre, se sente tratado de modo inferior, sem a atribuição de um devido valor. É um so- 
frimento que é sentido pelo indivíduo, "mas a origem deste não advém do próprio sujeito, mas das intersubjetividades delineadas socialmente" (FERREIRA, 2011, p. 83).

Assim, os afetos apresentados são baseados em sentimentos de gratidão, proteção e amor, e produzem a proteção dos filhos aos pais, em especial, com a figura da mãe, que os faz transpor o cuidado e proteção do grupo familiar ao local de trabalho. 0 cuidado e o amor pelos pais vão se constituindo em uma preocupação diária, em especial, para aqueles cujos pais vão trabalhar à noite no aterro, pois eles têm consciência das condições a que estão expostos:

Jorge (13 anos): Eu já fui lá, olhar minha mãe trabalhar, ela foi trabalhar ontem à noite, ela chega hoje, de manhã. Tem vez, tia, que não tem nem água para beber. Muita gente não leva comida nem água.

Marina (12 anos): Um dia, eu tava lá e veio aquela freira, o povo da católica. Veio até comida para mim.

Alice (12 anos): Tia, as vez eu nem durmo. Dá para ouvir o barulho das carretas e do trator que amassa, lá do quarto.

Ao relatarem as condições de trabalho de seus pais, observa-se a dor e o lacrimejar dos olhos. Os participantes expressam a emoção de um sofrimento que envolve todo o corpo, e, embora reconheçam a importância do trabalho, não aceitam as condições às quais seus pais estão expostos. Os relatos demonstram que esses trabalhadores ainda precisam de outras formas de solidariedade, de serviços voluntários, executados por outros grupos, para poderem sobreviver às condições impostas aos que trabalham a céu aberto nos aterros, lixões e nas ruas. O sofrimento das crianças ultrapassa o que é visível, alojandose em seu ser, no decorrer de toda uma noite, enquanto seus pais trabalham.
É possivel inferir, por meio do relato de Alice, que a menina convive com um sofrimento que, embora não seja visto, é ouvido e fortemente sentido. 0 barulho das carretas que ela ouve a faz visualizar o cenário, devido a sua inserção nessa realidade. A velocidade com que caminhões e tratores trabalham dentro do aterro e as condições desfavoráveis que os catadores têm de enfrentar, como seres humanos, competindo com a energia e a velocidade dessas máquinas, tiram o sono da menina. E sua preocupação ainda aumenta pelo fato de sua mãe não aceitar que ela a ajude, com receio das histórias de estupros e outras violências, inclusive casos de prostituição, que chegavam ao conhecimento dela. Como Alice descreve: "ganhá dinheiro tia, para fazê aquele negócio, tia" (Alice, 12 anos).

Nesse contexto, meninos e meninas enfrentam também outras situações dificeis, como a ausência de pais e irmãos mais velhos; e alguns trechos de suas narrativas evidenciam essa dura realidade:

Paulo (11 anos): Tia, acharo um homem morto lá, minha mãe viu. Minha mãe falou que era igualzinho meu pai. Aí, eu fiquei com muito medo. Aí passou uma semana e ele foi lá [...]. Meu pai tá preso, mas tá perto de sair. Quando ele vem do saidão, ele trabalha mais minha mãe.

Kédma (10 anos): É muito triste vê o filho ser preso. Ele ajudava minha mãe, ele era o mais velho, foi ouvir os outro. Tia, minha mãe sofreu muito, não podia fazer nada. Ele apanhou muito. Ela só abraçou nós.

Paulo apresenta a insegurança e a fragilidade daqueles que têm vínculos com pessoas que estão no sistema prisional. Esse movimento só é interrompido quando essas crianças se encontram com as famílias nos denominados "saidões", expressão utilizada quando seus pais têm a autorização, no decorrer de feriados, para visitar a família. Os meninos falavam do "saidão" dos pais e 
irmãos mais velhos com euforia, como uma forma de poder estar com eles, mesmo que por poucos dias.

Nesses momentos, pais e irmãos saem do processo de marginalização e são vistos como heróis. Os estudantes recordam os períodos em que conviviam juntos. 0 processo de afastamento dos pais e irmãos não os faz perder a referência e o sentimento familiar da convivência em grupo. Criam, mesmo que no imaginário, a figura materializada do herói.

Quando o relato se refere à prisão dos irmãos mais velhos, revela-se um sentimento de que houve algo que os fez perder a orientação, o sentido de ouvir a voz dos pais, dos professores, a voz dos mais velhos, considerados por eles como aqueles que têm uma determinada sabedoria. Kédma sente no próprio ser o sofrimento da mãe e dos irmãos mais novos e a presença do Estado - pois presenciou a prisão do irmão -, e identifica a impossibilidade de qualquer forma de reação, a não ser a de se acalentar nos braços da mãe. No grupo, ela buscava compreender as razões de seu irmão furtar objetos como celulares, enquanto afirmava que ele havia encontrado vários no lixão, mas considerava que a questão estava relacionada ao uso de drogas ilícitas.

\section{Imagem 01 - A família}

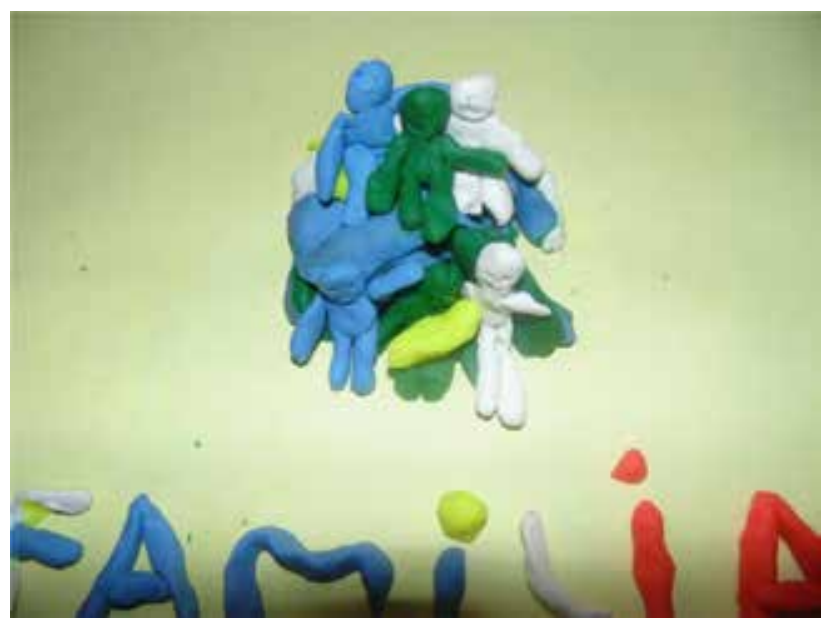

Fonte: modelagem da família/foto produzida por Luís, 12 anos.
Famílias que vão se constituindo de dores. Esses sentimentos, no entanto, vão produzindo elementos de luta e de união. Para eles, a família torna-se o grupo que os alimenta em todos os sentidos da dimensão humana. Mesmo nas adversidades da vida, eles vão se mantendo "juntos" e, em circunstâncias dificeis, vão criando estratégias para sobreviver e transformar a própria condição.

A Imagem 1 foi produzida em uma das oficinas autoecobiográficas, a partir de um trabalho com massa de modelar, em que era pedido que os participantes contassem o que foi significativo na oficina. Nessa imagem, o estudante produz a cena de uma família sentada em um só sofá. Ele interpreta que essa situação sempre acontece, quando se organizam para assistir televisão. Aqui, é retratada a dificuldade do grupo, pois residem em espaços pequenos e têm poucos móveis, a maioria doados e/ ou encontrados no aterro, situação comum a quase todos os colaboradores. 0 participante expressa que essa cena ocorre somente aos domingos no horário dos jogos de futebol. $\mathrm{Na}$ cena em questão estão representados um casal e quatro filhos; sendo que o casal está abraçado e os filhos estão dispostos ao seu redor. Para Luiz, essa configuração representa o que ele vive na realidade; mas ela também expressa o medo que ele tem de perder a mãe, pois, enquanto o menino moldava a imagem, ele relatava sua constante preocupação com a mãe, as voltas com hospitais, sem no entanto descobrir a causa de seu mal-estar.

Nesse cenário, é possivel perceber que as configurações familiares vão se apresentando sob diversas formas. Alguns moram com os pais biológicos; outros, com pai ou mãe e novos companheiros; e outros, ainda, com os parentes mais próximos, como os avós.

As narrativas dos participantes vão se constituindo como histórias que evocam um passado próximo, feito de muitas superações; e, nos 
momentos de silenciamento das oficinas autoecobiográficas, esses estudantes expressam seus desejos, indo na direção do material e de um universo ainda infantil; enquanto outros trazem o desejo de transformar o comportamento e as atitudes do próprio grupo familiar:

Ao final do encontro, como em todas as oficinas, paramos para o momento do autocuidado. Nesse momento, ficamos em círculo e vamos silenciando e ouvindo tudo que é externo a nós, perto e distante, e buscarmos perceber os barulhos do nosso corpo: coração, respiração etc. Hoje, pela segunda vez, observei a emoção trazida pelos meninos, ao expressarem as palavras que desejavam, nesse momento. Eram palavras embargadas de emoção, Desejos como: paz na Estrutural; paz para minha família; uma bicicleta para ajudar minha mãe; desejar que o avô pare de beber; 'ah tia, só paz, tá precisando muito lá', fala da Maria. (Diário de campo, 29/09/2014)

A questão do alcoolismo é considerada por todos os participantes como um problema, pois envolve violência doméstica, em especial, contra a figura materna, o que os leva a querer proteger suas mães dessas situações - muitas vezes, enfrentando com coragem aqueles que as ameaçam -, mas também os obriga a experienciar sentimentos de raiva e tristeza, como os relatados a seguir.

Laudiceia (10 anos): Eu vou contar uma coisa, mas ninguém pode contar pra minha mãe, se não (faz gesto de bater e ri muito). Tia, meu padrasto bate na minha mãe. Não é para contar, viu gente. É que minha mãe me mata, se eu falá. Falei tia, falei mermo que eu vou matar meu padrasto. Não aguento mais, ele bate na minha mãe à noite, quando chega da rua. Eu falei pra ele mermo.

Ao falarem de suas famílias, os participantes relatam comportamentos agressivos dos padrastos, pais e irmãos mais velhos. A narrativa de Laudiceia é carregada de dor e indignação, e de uma profunda raiva por presenciar sua mãe ser espancada pelo padrasto. Ao fa- lar que mataria o padrasto, a menina revela o desejo de livrar-se do grande responsável por impor àquele grupo um sofrimento diário. Mas sua raiva também deriva do fato de não concordar que sua mãe não o denuncie.

Desse modo, esses estudantes, em suas narrativas, evidenciam processos de reflexão sobre a dureza de suas realidades, de forma consciente; e apresentam problemas que se assemelham entre si, como a questão do alcoolismo dos pais. Diante desse problema, os participantes parecem buscar estratégias para a resolução dos conflitos que não excluam do núcleo familiar o responsável pelo sofrimento, o que evidencia sua esperança na família e na superação da condição de violência.

Durante a realização da pesquisa, esses participantes narravam essas situações e discutiam uns com outros, buscando encontrar formas de solucionar alguns desses problemas. Além disso, revelavam no grupo segredos que gostariam de compartilhar com o personagem Carniça, e que acordavam entre si que seriam guardados, o que acabava fazendo com que alguns questionassem na chegada ao grupo se o outro havia contado a alguém sobre "aquilo que falei naquele dia", fala sempre recorrente.

Eles faziam gestos e batiam uma mão na outra, como forma de estabelecer um compromisso. Eram crianças e adolescentes refletindo sobre uma realidade severa, mas que estabeleciam momentos de uma fantasia própria do período etário em que estavam, e tinham segredos como que guardados em um baú. Afetos que se constituíam de sofrimentos e alegrias e iam se estabelecendo, ao narrarem suas relações familiares.

As narrativas iam apontando o sentimento de orgulho que desenvolveram por seus pais, em especial quando havia questões relacionadas à honestidade deles, como no relato de Luana. 
Luana: Meu pai achou quatrocentos reais, mas meu pai levou lá no conselho Tutelar, para vê lá de quem era. Aí o Conselho disse que meu pai podia ficar, meu pai ficou, tá lá em casa, mas ele não gastou por coisa nenhuma. Pro que se o Conselho Tutelar falar que é de uma pessoa, aí meu pai vai devolver.

Emocionei-me com a situação, estava eu e um grupo de crianças fotografando os espaços da Estrutural, que eles gostariam de levar para a escola, e passaram, próximo de nós, várias famílias de bicicleta. Neste dia, descobri que é um dos meios de transporte mais usados ali. Entre as famílias, estava a família de Luana. Todos de bicicleta, o pai levava a filha mais nova em uma cadeirinha, e ela e a mãe, cada uma com uma bicicleta. Ela parou, ao nos ver, e todos vieram em nossa direção. Ela repetia a história que me contou sobre o dinheiro e pedia que os pais a confirmassem. A sua confirmação trouxe a todos (família) uma carga de orgulho, por terem feito aquela ação que os fazia ser considerados pessoas honestas. (Diário de Campo, 06/12/2014)

São famílias que, mesmo diante dos sofrimentos, trazem valores alicerçados na honestidade e no respeito, e buscam transmiti-los a seus filhos, a partir de seus comportamentos e atitudes, diante de situações como a relatada acima. Alguns colaboradores falavam de documentos que eram encontrados no aterro por seus pais, e logo devolvidos; e de situações em que ocorriam acidentes com vizinhos, no período da noite, e seus pais acordavam para ajudá-los. Contavam ainda sobre as mães que, mesmo chegando do trabalho noturno, pela manhã, faziam o cuscuz, para que os filhos não saíssem sem a primeira refeição do dia.

Reinaldo (12 anos) trouxe uma definição de família de forma coerente: "ah tia, é assim um monte de gente, tem dia que é bom, tem dia que é ruim". São seres afetados diariamente pelos indivíduos com os quais coabitam, e pela realidade social precária que acentua a violência e a miséria, tanto na sociedade como nos pequenos grupos, como a família. Esses meninos e meninas constroem afetos de amorosidade, compromisso, mas também de indignação e raiva, quando acreditam que naquele grupo familiar não cabe violência e desrespeito. Eles estão dispostos a contribuir, e buscam uma maior compreensão entre todos os que constituem aquele ambiente.

\section{A ausência da escolarização e a busca da educação como valor}

Nesses grupos familiares, todos estão em um processo de aprendizagem, alguns muito jovens, para serem pais e mães, e outros, para quem a própria exclusão trouxe dores irreversiveis, exercitadas nas relações, mas que lutam diariamente para tecer uma nova roupagem para sua condição, como a de acompanhar e mobilizar os filhos para a educação como um valor. Mulheres que, mesmo subjugadas pela violência e a opressão, produzem um discurso de esperança, no sentido do saber.

Essa experiência foi visualizada quando fiz o trajeto para chegar a uma reunião de pais que aconteceria na Cidade Estrutural. Várias cenas foram compondo os movimentos da cidade. Eram pais chegando de bicicleta; outros a pé, acompanhados dos filhos, a grande maioria jovens. A reunião acontecia em um galpão, em que cada professor ocupava um canto do local, aguardando os pais. A maioria dos pais chegava de mãos dadas com os filhos e se aproximava de seus professores. Em alguns casos, observava-se uma relação de parceria, no sentido de demonstrarem, através de gestos e falas, que ali se encontravam pessoas que estavam dispostas a contribuir umas com as outras. Alguns trocavam apertos de mão e abraços.

Nesse universo, duas crianças esperavam a uma certa distância de seus pais. Demonstravam nervosismo por não saberem suas notas. Uma delas ainda dava palpites sobre o valor 
da média. Era uma demonstração da sua preocupação, como estudante, em ver o seu reconhecimento, a partir de seu mérito. Como ali era a nota que demarcava esse valor, a preocupação era válida.

Observou-se que alguns pais, ao se aproximarem, demonstravam medo e receio de receberem notícias desagradáveis. Duas mães traziam um elemento diferenciado a esse ambiente: a emoção, ao saberem do desenvolvimento dos filhos. Uma tentava controlar as lágrimas, mas, ao deixar o espaço onde acontecia a reunião, deixou as lágrimas caírem e saiu abraçada à filha. A outra teve 0 mesmo procedimento, mas seu choro era de tristeza; e ela comentou com a amiga ao lado que já não sabia como sair daquela situação, pois, segundo ela, seu filho não queria mais estudar.

Esses elementos demonstram a preocupação desses pais com a vida escolar de seus filhos, mesmo que alguns não tenham uma escolaridade para compreender alguns conceitos que os professores utilizam para explicar a condição e situação de aprendizagem dos estudantes. Esse fato era notório pela expressão em seus rostos. Também se evidenciava quando uma mãe se aproximava e pedia para outra pessoa the explicar o que estava escrito, pois não havia entendido o que o professor disse. Essas situações os levam a conhecer o sucesso ou o fracasso, mas não há entendimento do processo de ensino aprendizagem.

O processo de escolarização vai se constituindo dos sonhos daqueles que não tiveram acesso à escolarização, como nos relatos a seguir:

Antônio (11 anos): A minha mãe fala que ela manda eu sempre estudar para sê alguém na vida. Quando eu crescer né.

Kédma (10 anos): a gente fala para nossa mãe que a gente quer aprender, qué tê vontade de sê alguém na vida, aí ela fica feliz. Muito! Ela diz que tem gente que não qué e que não pode igual nós.

Ana (12 anos): meu pai veio para cá pra mim estudar, mas eu acho que ele quer ir embora de novo pra Pernambuco.

São mães e pais que buscam, na ausência da escolarização, uma justificativa para encaminhar seus filhos para a escola. Sentem as alegrias do progresso escolar e a tristeza de enxergar que alguns poderão repetir seus caminhos, abandonando a escola por não conseguirem conciliá-la com o trabalho. Provavelmente, os que trilharem o caminho da catação, como seus pais, irão atribuir a ausência da escola ao sofrimento que passaram no processo de viver da catação. Esse grupo familiar produz o eco da escola em uma constituição utópica de que é a partir daquele ambiente que eles irão transformar suas vidas, ter vidas diferentes das que seus pais tiveram. Alguns desses pais não percebem que são heróis diante desses estudantes e que a figura materna é vista pela maioria como uma força motriz que alicerça esse núcleo. Assim, a escola é apresentada pela família como uma possibilidade de fazê-los alavancar para o universo de profissões consideradas por seus pais melhores do que aquelas em que eles próprios atuam no presente.

\section{Considerações}

0 trabalho se constitui como a base dessas famílias. Ele se mistura ao viver familiar, trazendo hábitos e costumes próprios. Alguns desses estudantes participam do trabalho dos pais; outros vão ao lixão para recolher brinquedos; e outros, ainda, só conhecem a realidade do trabalho no lixão pelas histórias contadas pelos pais e irmãos mais velhos, já que seus pais não permitem sua presença naquele local.

No que diz respeito aos últimos, a atitude de seus pais de os manter longe da dura 
realidade do lixão revela uma preocupação e um cuidado de preservar a infância de suas crianças, preocupação essa reforçada pela ação de recolher em seu ambiente de trabalho alguns brinquedos e objetos escolares para elas. O eco da educação vem dos pais, como uma preocupação com a formação dos filhos. E essa preocupação, na maior parte das vezes, vem mais especificamente da figura materna, que, diante da ausência da escolarização para si mesma, acredita que o sonho de uma transformação de vida venha pelo viés da educação escolar.

A figura materna, nesse contexto, muitas vezes tem de abarcar a dimensão do cuidado no núcleo familiar, responsabilizando-se pela luta diária para manter a família próxima, para dar subsídio material e afetivo a esse grupo familiar, e assegurar o direito deles a um lar. Nesse sentido, essas mulheres tornam-se guardiãs desse território simbólico que é a família. São núcleos familiares em que se constroem relações de amorosidade em meio à imersão na vulnerabilidade pelo processo de exclusão que vivem. Concomitantemente, essas mães vivenciam o processo de obterem cuidado e proteção de seus filhos quando participam de trabalhos noturnos e quando a figura paterna e os irmãos mais velhos estão no sistema prisional. Isso faz com que essas crianças e adolescentes tragam para si a responsabilidade de cuidar de suas mães e de estar com elas nesses períodos. Isso também produz o sentimento do medo e da insegurança de perdê-las. Quando as mães enfrentam a violência doméstica - problema presente em todas as classes sociais, e em que o alcoolismo é apontado como a principal causa -, os filhos experimentam sentimentos de indignação e de dor, mas alimentam também a esperança de uma busca contínua pela paz, na perspectiva de acreditarem que podem, conjuntamente, buscar uma solução para essa condição.
Na configuração desses lares, há também a figura masculina, sempre relacionada aos pais e irmãos mais velhos. Mesmo que estejam ausentes dos núcleos familiares devido a questões prisionais, os colaboradores da pesquisa nutrem por esses pais e irmãos um sentimento de amorosidade baseado na figura do herói e na expectativa do reencontro, na esperança do retorno dessas pessoas ao grupo familiar. Em casos específicos, há também a figura paterna lutando pela guarda dos filhos de modo a preservar sua integridade moral e física, quando a mãe é a causadora das situações de conflito, e coloca a vida de seus filhos em risco em razão do uso de drogas, entre outros.

É possivel inferir que essas são famílias forjadas na dor e na alegria do sobreviver e do conviver diários, que trazem para seu interior as mazelas causadas pelos problemas socioambientais e pela inclusão precária que enfrentam, mas cultivam a amorosidade e alimentam a esperança de dias melhores. Constituem-se por valores como a honestidade, o cuidado e a perseverança em manter aceso o sonho de permanecerem juntos na luta constante pela valorização de um trabalho pouco ou nada reconhecido socialmente. Por último, os estudantes colaboradores revelam o desejo de promover uma transformação em suas vidas por meio da escolarização e da valorização do ofício de seus pais, para o estabelecimento da paz e do viver digno em sua comunidade e em seu núcleo familiar.

\section{Referências}

ALTERTHUM, Camila Carvalhal. 0 encontro com crianças filhas de catadores de papel: sinalizações para uma creche e uma pesquisa com a "nossa cara". Belo Horizonte, 2005. p.126 Dissertação (mestrado em Educação) - Universidade Federal de Minas Gerais; 2005.

BARBOZA, Daiani. As múltiplas cidades na cidade: as 
relações estéticas dos catadores de material reciclável com a polifonia urbana. Santa Catarina, 2013. 276p. Tese Doutorado em Psicologia. Universidade Federal de Santa Catarina; 2012.

BENSEN, Gina Rizpah. Sustentabilidade dos Programas de coleta seletiva com Inclusão social: Avanços, desafios e indicadores. IV Encontro Nacional da ANPPAS, 4,5,6 de julho de 2008. Brasília, DF, Brasil. Disponivel em: <www.anppas.org.br/encontro4/CD/ ARQUIVOS/GT640313520080509143212.pdf>. Acesso em: 12 fev. 2013.

BENSEN, Gina Rizpah. A coleta seletiva com inclusão de catadores: construção participativa de indicadores e índices de sustentabilidade. São Paulo, 2011. 275p. Tese Doutorado em Saúde Pública. Universidade Federal de São Paulo; 2011.

\section{BIRKBECK, C. Self-employed proletarians in an In-} formal factory: the Case ofCali's garbage dump. World Development Journal, v. 6, n. 9/10, p. 11731185, 1978. Disponivel em: <http://previous.wiego. org/publications/RegionCountry/LatiAmerica/ Birkbeck_self_employed_proletarians.pdf> Acesso em: 10 jul. 2013.

BOIS, Danis; AUSTRY, Didier. A emergência do paradigma sensivel. Revista @mbienteeeducação. São Paulo, v.1, n.1. p. 1-20, jan/jul. 2008. Disponivel em: <https://wp.ufpel.edu.br/gepiem/files/2008/12/a_ emergen.pdf>Acesso em :20 agos.2020.

[CENTRO DE DOCUMENTAÇÃO E INFORMAÇÃO DO INSTITUTO PÓLIS] Coleta Seletiva com inclusão dos catadores. São Paulo, 2007. Disponivel em: <http:// www.polis.org.br/uploads/1008/1008.pdf>. Acesso em: 10 jan. 2013.

COSTA, Cláudia Moraes da. Reciclagem e Cidadania: a trajetória de vida de catadores de material reciclável. Brasília, 2008. 155 f. Dissertação Mestrado em Educação - Universidade de Brasília; 2008. Disponivel em: <http://repositorio.unb.br/bitstream/10482/1889/1/2008_ClaudiaMoraesCosta. pdf>. Acesso em: 12 ago. 2012.

COSTA, Cláudia Moraes. A práxis do viver como epistemologia: o saber sentido da/na escola como forma de emancipação da condição humana no viver na terra, 2016. 261f. Tese de Doutorado em Educação - Universidade de Brasília; 2016. Disponível em: http:// repositorio.unb.br/handle/10482/21924>. Acesso: 16 de dezembro de 2019.

COSTA, Cláudia Moraes; PATO, Cláudia. Oficinas autoecobiográficas: território do criativo e do diverso. VIII Congresso Internacional de Pesquisa (Auto)Biográfica, edição 8á, 2018, São Paulo. VIII Congresso Internacional de Pesquisa autobiográfica, Anais... São Paulo: BIOgraph, 2018. p. 1-18.

COSTA, Cláudia Moraes; PATO, Cláudia. A constituição de Catadores de materiais recicláveis: identidade estigmatizada pela exclusão e a construção da emancipação como forma de transcendência. PEREIRA, Bruna Cristina Jaqueto; GOES, Fernanda Lira. Brasília Catadores de Material Reciclável: um encontro nacional. Rio de Janeiro, IPEA, 2016. p. 99-121.

DELORY-MOMBERGER, C. Biografia e Educação: Figuras do indivíduo-projeto. Trad: Maria da Conceição Passeggi, João Gomes da Silva Neto e Luis Passeggi. Natal: EDUFRN; São Paulo, SP: Paulus, 2008.

Formação e socialização. Os ateliês biográficos de projeto. Educação e Pesquisa, São Paulo, v.32, n.2, p.359-371, 2006.

DIAS, Sônia Maria. Trajetórias e memórias dos Fóruns Lixo e Cidadania no Brasil: experimentos singulares de justiça social e governança participativa. Belo horizonte, 2009. 339 f. Tese Doutorado em Ciências Políticas - Universidade Federal de Minas; 2009.

FEITOSA, Larissa de Brito. Sentidos atribuídos às políticas públicas de inclusão dos catadores pelos atores envolvidos nas discussões dos resíduos sólidos. 2011. 151 f. Dissertação (Mestrado em Psicologia. Programa de Pós-graduação em Psicologia, Universidade Federal do Ceará, Fortaleza, CE, Brasil, 2011.

FERREIRA, Carla Patrícia Martins. A formação do sentido e o sentido da vida: o Círculo ecobiográficos com educadores e as experiências afetivas formadoras em sua relação com o semiárido cearense. Ceará, 2011. 190 f. Tese (Doutorado em Educação) - Programa de Pós-graduação em Educação. 
Universidade Federal do Ceará; 2011. Disponível em: <http://www.repositorio.ufc.br/bitstream/riufc/3357/1/2011_Tese_KPMFerreira.pdf>. Acesso em: 6 jul. 2015.

FREIRE, Paulo. Pedagogia da Autonomia: saberes necessários à prática educativa. 6ed. Rio de janeiro. Paz e Terra. 1997.

IBGE - INSTITUTO BRASILEIRO DE GEOGRAFIA E ESTATÍSTICA. Censo Demográfico 2010: resultados preliminares do universo - conceitos e definições - tabelas adicionais. Rio de Janeiro: IBGE, 2011.

IPEA. Diagnóstico sobre catadores de resíduos sólidos. Relatório de Pesquisa. Brasília: Ipea, 2012JANUZZI, Paulo de Martino. Indicadores sociais no Brasil. Campinas: Alínea, 2001.

JOSSO, Marie-Christine. As histórias como territórios simbólicos nos quais se exploram e se descobrem formas e sentidos múltiplos de uma existencialidade evolutiva singular-plural. In: PASSEGGI, Maria da Conceição (Org.). Tendências da pesquisa (auto) biográfica. Natal: EDUFRN; São Paulo, SP: Paulus, 2008. p. 23-50.

JOSSO, Marie-Christine. Da formação do sujeito... Ao sujeito da formação. In: NÓVOA, Antônio; FINGER, Mathias (orgs.). 0 método (auto) biográfico e a formação. São Paulo: Paulus, 2010. p. 59-79.

LECHNER, Elsa. Oficinas de Trabalho biográfico: pesquisa, pedagogia e ecologia de saberes. 2012. Educação Rel. Porto Alegre, v. 37, n.1.p.71-85, jan/abr. Disponível em: <Seer.ufrg.br/educaçãoerealidade/ article/viewfile/21807/16032> Acesso: 2 maio 2013.

MAGERA, Márcio. Os caminhos do lixo: Da obsolescência programada a logística reversa. São Paulo: Atomo Alinea, 2012.

MELO FILHO, Benício de. O valor econômico e social do lixo de Brasília. Curitiba: Universidade Federal do Paraná. 2005.

MORÃO, Laís. Educação Ambiental e Ecologia Humana, fundamentos para um debate. Linhas Críticas, 1996.p.32-40,v.2.n.2.Disponível em:.https://periodicos.unb.br/index.php/linhascriticas/article/ view/2609. Acesso em: 7 de fev. de 2020.
MORIN, Edgar. O Método II, a vida da vida. IN: A autonomia fundamental" Autos: Porto Alegre: Sulinas, 2005. p. 123-181.

NÓVOA, Antônio; FINGER, Mathias (orgs.). 0 método (auto) biográfico e a formação. São Paulo: Paulus, 2010.

OLIVEIRA, Jairo Anderson; FERNANDES, Sheila Christiane S; ALMEIDA, Saulo S.M. Análise de Representações Sociais de Catadores de Lixo de Sergipe Acerca de sua realidade Social. PSICO, Juiz de Fora, jan./ mar. 2012.p. 55-68, v. 43, n.1.

PASSEGGI, Maria da Conceição et al. Narrativas de crianças sobre as escolas da infância: cenários e desafios da pesquisa (auto)biográfica. Educação, Santa Maria, v. 39, n. 01, p. 85-104, 2014. Disponível em: http://cascavel.ufsm.br/revistas/ojs-2.2.2./index.php/reveducacao/article/view/11345. Acesso em: 20 fev. 2020

PÓLIS- INSTITUTO PÓLIS. Documento Encontro Nacional, 2006. Construindo Políticas Públicas para a Recuperação e Reciclagem de Resíduos Sólidos com Inclusão dos Catadores. Instituto Pólis, 2006.

SAWAIA, Bader Burihan. 0 sofrimento ético-político como categoria de análise da dialética exclusão/ inclusão. In: SAWAIA Bader Burihan. Artimanhas da exclusão: Uma análise psicossocial e ética da desigualdade social. Petrópolis: Vozes, 1999. p. 97-118.

SOUZA, Elizeu Clementino. 0 conhecimento de si: narrativas do itinerário escolar e formação de professores. Bahia, 2004. 337 f. Tese (Doutorado em Educação) - Programa de Pós-graduação e, Educação, Universidade Federal da Bahia; 2004. Disponível em: <https://repositorio.ufba.br/ri/bitstream/ ri/10267/1/Tese_Elizeu\%20Souza.pdf.>. Acesso em: 10 jul. 2014.

SOUZA, Elizeu Clementino. A arte de contar e trocar experiências: reflexões teórico-metodológicas sobre história de vida em formação. Revista Educação em Questão.v. 25, n. 11, p. 22-39, 2006. Disponível em: <http:www.revistaeduquestao.educ.ufrn.br/ pdfs/v25n11.pdf> Acesso em jun.2018

TEIXEIRA, Marília Magalhães. Realidade Revelada: os catadores informais de materiais recicláveis no 
contesto da Universidade de Brasília, 2010. 189 f. lia; 2010. Disponível em: <http://repositorio.unb.br/ Dissertação de Mestrado- Universidade de Brasí- handle/10482/7136>. Acesso em: 25 jul. 2014.

Recebido em: 04/03/2020

Revisado em: 04/08/2020

Aprovado em: 20/09/2020

Cláudia Moraes da Costa Vieira é doutora e mestre em Educação pela Universidade de Brasília (UnB). Área de pesquisa: Educação Ambiental e Educação do Campo. Professora da Secretaria de Estado de Educação do Distrito Federal. E-mail: claudia.morasdacosta@gmail.com 